$23-28$

\title{
太湖定振波的初步研究
}

\author{
(中国科学院南京地理与胡泊研究所.南京 210008)
}

提要初步分析研究了太湖定振波的变化规律、结果表明:(1)东、西太湖有各自的振动 周期, 东太湖变化范围在 181--292 min, 平均为 $243 \mathrm{~min}$; 西太湖在 $120-540 \mathrm{~min}$, 平均为 $400 \mathrm{~min}$ 。 (2)现测到的最大振堛(1/2 波高)为 $120-130 \mathrm{~mm}$ 。（3)用差分法对定振波的特征值进行了近似 估算,其周期误差为 $20 \mathrm{~min}$ 。(4)定振波引起的湖流相当大,当振幅为 $100 \mathrm{~mm}$ 时，最大流速可达 $\pm 20 \mathrm{~cm} / \mathrm{s}$ 。(5)定振波振幅的实变与氠场、风场和降水分布不均匀并在短期内发生突变有关。

\section{关转词定振波 太湖。基本特征。}

为了研究太湖定振波的基本特征.1984 年 4 月至 1987 年 6 月,在太湖的东部油车港. 西部大浦・南部顾家斗, 北部吴塘门设置丁自记水位计,风向风速计,自记雨量计等(图 2), 积累丁较多的定振波及风涌水资料,本文将对太湖定振波的基本特征作一分析。

\section{一、太湖定振波的一般特征}

太湖湖盆呈不规则分布、除西南岸呈圆弧状外，其它部分的岸线极不规则。因而定振波 现象十分复杂, 同一地点不同风向风的作用下振荡的水平范围 $(L)$ 也不同. 因而周期 $(T)$ 也不同、资料表明、太湖存在着多种周期选加的定振波 (图 1)。定振波周期的变化范围为 10-1200 min。而周期在 330-420 min 的占资料的 50\%在右, 平均周期 ( $\bar{T}$ ) 约为 $400 \mathrm{~min}$, 各 测点间周期较为接近。

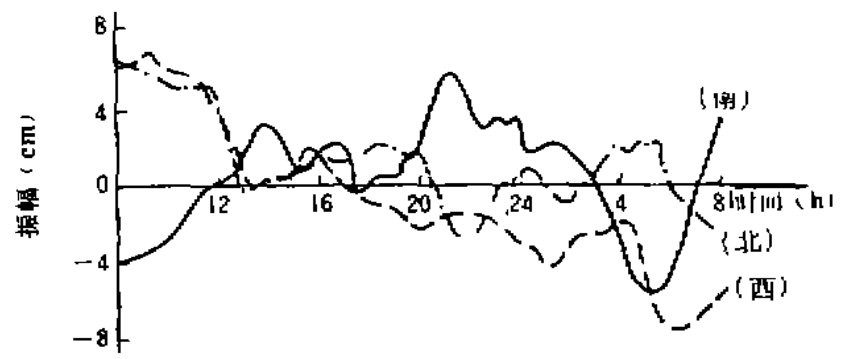

图 1 太湖定振波实测(1986 年9月28日1

Fig. 1 The case of seiches in Taihu Lake

太湖系一浅水湖泊，定振波周期随水位变化而显著变化，水位变化 $20 \mathrm{~min}$, 周期变化 $22 \mathrm{~min}$ 左右。其实测值最大振幅 ( $1 / 2$ 波高) 南部为 $100 \mathrm{~mm}$, 北部为 $120 \mathrm{~mm}$, 西部为 $90 \mathrm{~mm}$, 东 部为 $130 \mathrm{~mm}$ 。 


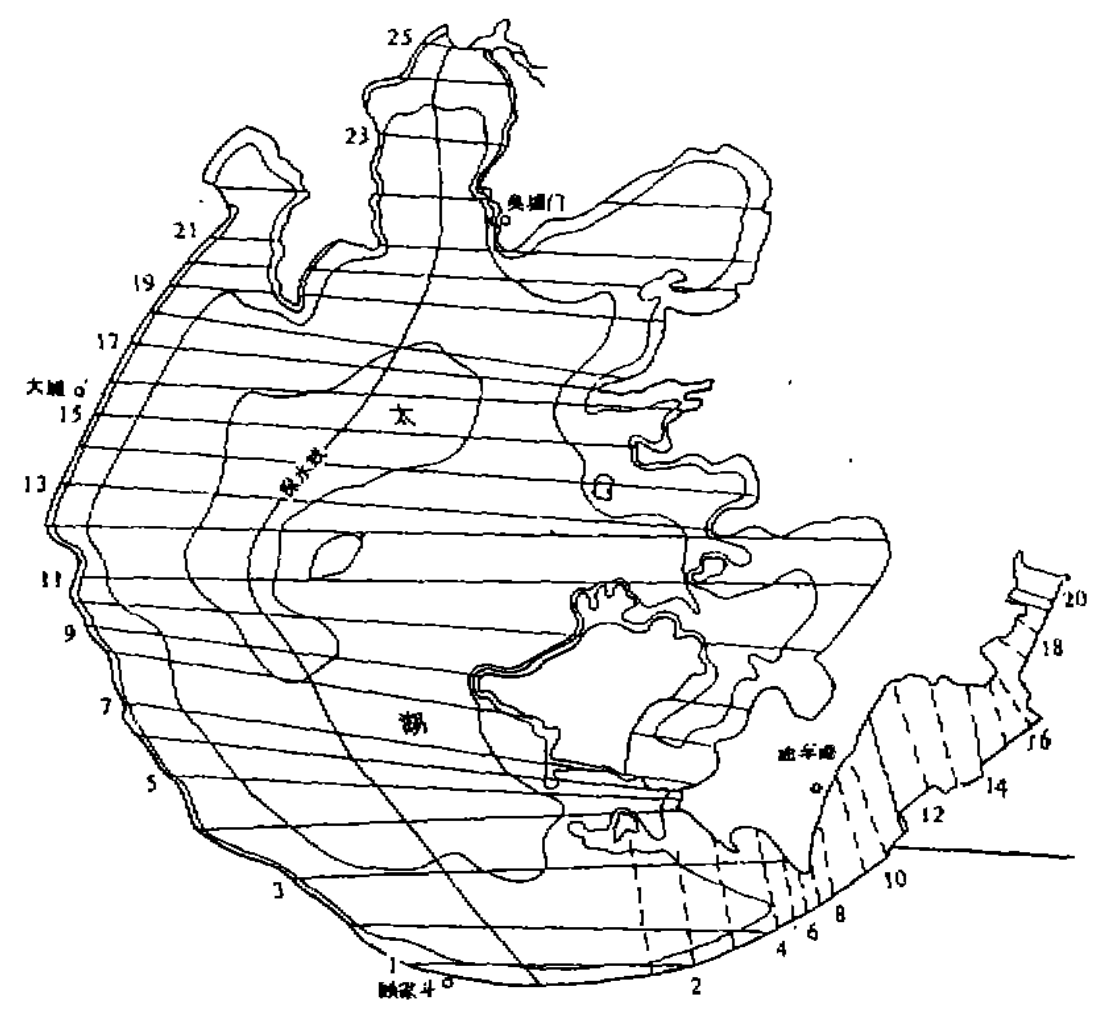

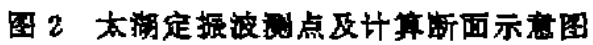

Fig. 2 Measurement points and profile calculation of seiches in Taihu Lake

东太湖定提波周期和振幅的变化与西太湖有所不同。如长时间受偏西大风影响,其周期 明显加大, 振幅显著增高。通常情况下主振波周期在 $181-292 \mathrm{~min}$, 平均约 $243 \mathrm{~min}$ 。当较长 时间为静风时, 较大湖湾内的定振波亦各自有其自己的振动周期和变化规律, 如无钽湾无风 情况下周期为 $180 \mathrm{~min}$. 在风作用 10 小时后，受大湖面振荡的影响、周期与大湖面揞与一致。

\section{二、太湖定振波的数值估算}

\section{1，定振波的数学模式}

定层波又称觧振，是一种波长与湖泊长度为同一量级的长波驻波运动。19世纪以来人 们对它进行了观测和研究，梅良首先提出了水深一致的长方形湖盆定振波的数学模式。假定

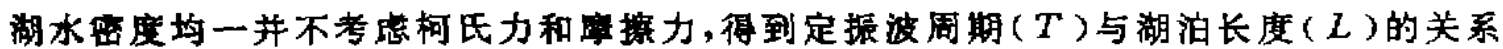
式 ${ }^{[2]}$ :

$$
T=2 L / n \sqrt{g} \bar{h}
$$

其中 $n$ 为定振波节点数, $h$ 为平均水深, $g$ 为重力加速度。

由于湖盆的形状千差万别,公式(1)计算误差较大。1928 年德方特应用流体力学方程的 
数值积分法.得出一个简便的数学模式用以估算不同形态湖泊的定振波周期、断面铅直和水 平位移以及节线位置等。

在宽度为 $b$. 横断面面积为 $s$ 的湖泊内. 自由振动的动力方程和连续方程可简化为 ${ }^{[1]}$ ：

$$
\begin{gathered}
\frac{\partial^{2} \xi}{\partial x^{2}}=g \frac{\partial \eta}{\partial x} \\
\frac{\partial(S \xi)}{\partial x}=-b \eta
\end{gathered}
$$

假定铅直位移和水平位移均作如下的周期变化:

$$
\left.\begin{array}{l}
\xi=\xi(x) \cos \frac{2 \pi}{T} t \\
\eta=\eta(x) \cos \frac{2 \pi}{T} t
\end{array}\right\}
$$

将方珪(4)中的微分用微量 $\Delta \xi$ 和 $\Delta \eta$ 来代替, 使得

$$
\Delta \eta=\frac{4 \pi^{2}}{g T^{2}} \xi \Delta x, \xi=-\frac{1}{S} \int_{0}^{x} \eta b d x
$$

用中心差分法计算，假定各棤断面相距很近，位移变化是线性的,则方程 (5) 可改写成：

$$
\begin{aligned}
& \eta_{1}=\eta_{i-1}+\alpha_{1} \frac{\xi_{i}+\xi_{1-1}}{2}, a_{1}=\left(\frac{4 \pi^{2}}{g T^{2}}\right) \Delta x_{1} \\
& \xi_{2}=-\frac{1}{S_{1}\left(1+\frac{\alpha_{1} v_{i}}{4 S_{1}}\right)}\left[q_{1-1}-\left(\eta_{1-1}+\alpha_{1} \frac{\xi_{i-1}}{4}\right) v_{1-1}\right] \\
& g_{i}=q_{i-1}+\Delta q_{1}, \Delta q_{1}=-v_{1} \frac{\eta_{1}+\eta_{1-1}}{2}
\end{aligned}
$$

在 (6) 式中， $\eta_{1}, \xi_{1}, S$, 分别为 $i$ 断面的铅直位移, 水平位移和面积; $\Delta x$ ，和 $v_{1}$ 为 $i$ 和 $i-1$ 断面间的距离和水面积; $q,=S, \xi$ ，为通过 $i$ 断面的水流容积。

计算中周期 $T$ 的初始值由(1) 式确定，计算从湖泊的一端开始 $(x=0)$ ，此处 $\xi_{0}$ 和 $g_{0}$ 为 零, 而 $\eta_{0}$ 可取任意值，根据湖泊地形图量出 $\Delta x_{1}, s_{1}, v_{i}(i=0,1,2,3, \cdots \cdots, n)$ 等,用方㮒 (6) 逐 步地计算出湖泊内各个断面上位移值。选择适当的 $T$, 使 $x=0, x=L$ 处能满足 $\xi_{0}=\hat{\xi}_{L}=0$. $q_{0}=q_{L}=0$ 的边界条件。由于地形测量及计算误差、所以边界条件只是近似的满足。

\section{2. 估草结是}

按 (6)式对太湖定振波特征值分东、西太湖两部分进行计算,并各取20个和 25 个断面.见 图2.西太湖深水线呈南北走向、长度为 $66.8 \mathrm{~km}$. 当平均水位为 $3 \mathrm{~m}$ 时,算得单节点定振波周 期为 $397.5 \mathrm{~min}$. 比实测值小 $20 \mathrm{~min}$ 。造成误差的原因系测量误差及湖中有岛屿等。图 3 是西太 湖定振波特征计算结果的一例 ( $T=397.5 \mathrm{~min}$ )。上半部是各个断面的铅直位移(相对于南 部振幅为 $5 \mathrm{~cm})$ 和 $1 / 2$ 周期内输送容积 $\left(\mathrm{m}^{3}\right)$, 图的下半部是 $1 / 4$ 周期内总水平位移和最大流 速，即平均流速 $\left(\frac{4 \xi}{T}\right)$ 乘以 $\frac{\pi}{2}$ 。图了的所有标尺将随定振波振幅的增大而增大。

计算结果表明，当周期为 $397.5 \mathrm{~min}$ 时，振幅为零的节点线位于漫山盘至兰山嘴一线，此 处接近全湖的 $1 / 2$ 处。水平位移最大值达 $\pm 390 \mathrm{~m}$, 位于 7 号断面附近, 此处水面最窄、相应有 

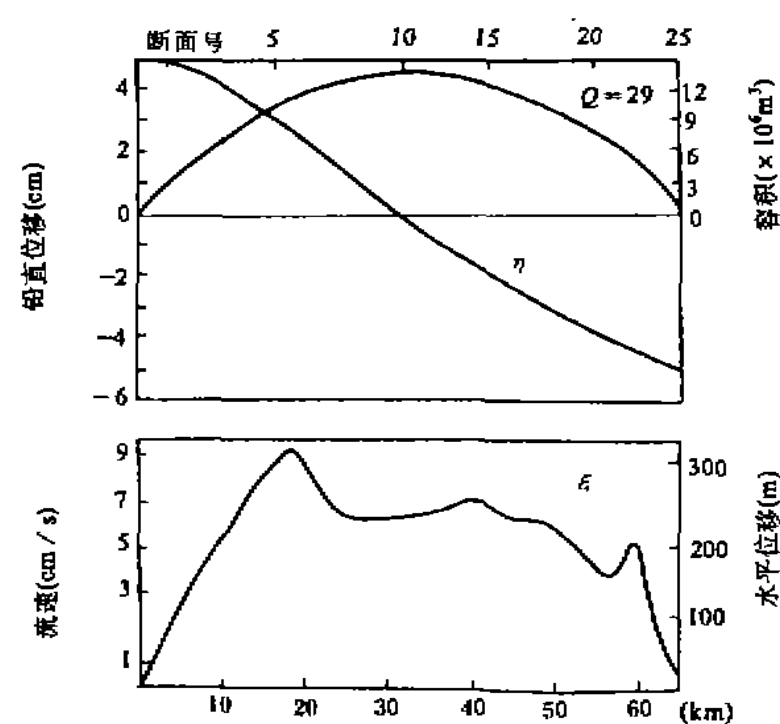

图3太湖定振波特征计算值

Fig. 3 Characteristic value of seiches in Taihu Lake

最大水平流速 $(10.6 \mathrm{~cm} / \mathrm{s}) .10$ 至 12 号 断面是全湖最宽处, 这里有最大的水 量水平输送,在半个周期内达到 $13 . ?$ $\times 10^{6} \mathrm{~m}^{3}$ 。

东太湖计算结果表明, 当周期为 $200 \mathrm{~min}$ 时.定振波节点位于杨湾束水 口外 $5 \mathrm{~km}$ 左右的地方。当 $\eta=5 \mathrm{~cm}$ 时. 最大水平流速可达 $12 \mathrm{~cm} / \mathrm{s}$ 左右。1984 年7月围网区同步资料表明污, 上述计 算结果是可靠的。同时还表明，定振波 作用能改变湖流的流速和流向。

由于太湖地形较复杂、深度较浅， 湖中岛岾较多・且各个湖湾亦有各自 的变化规律、上述估算只能作为某一 水深状态下的近似结果。

\section{3. 定振波衰减系数的估算}

在定振波运动过理中、湖底的阻 尼作用将使振幅逐渐减少, 振动周期也略有减少,定振波振幅的衰减规律可用指数形式表 示:

$$
A_{i}^{*}=\exp \left(-\nu_{n} \cdot n\right) \text { 或 } A_{t}^{*}=\exp \left(-\nu_{t} \cdot t\right)
$$

式中 $A_{n}^{*}=A_{n} / A_{0}, A_{i}^{*}=A_{t} / A_{0}$, 分别为第 $n$ 个波和 $t$ 时刻的相对振幅. $A_{n}, A_{z}, A_{0}$ 分别为 第 $n$ 个波和 $t$ 时刻及初始时刻的振幅.显然;

$$
\nu_{z}=\nu_{n} / T
$$

$\nu_{\mathrm{r}}$ 和 $\nu_{\mathrm{n}}$ 称为衰减系数, 为减少偶然性误差, 估算时, 取三个相猞波幅的算术平均值为该 时段的平均相对振幅,在波数 $n$ 和相对振幅 $A_{n}^{*}$ 的半对数座标中,得一回归方程.由此确定

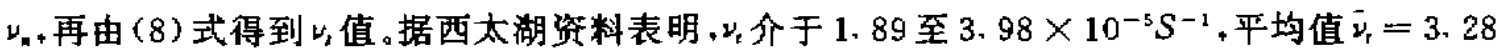
$\times 10^{-5} S^{-1}$; 东太湖的 $\bar{r}_{2}=4.61 \times 10^{-5} S^{-1}$ 。与日本琵琶湖南部 $\left(3.12 \times 10^{-5} S^{-1}\right)$ 相近。

太湖定振波衰减速度较快 3 个个周期即衰减 $70 \%$ 左右, 具有浅水湖泊衰减规律的显著特 征。比云南抚仙湖衰减速度快23倍。

湖底摩擦力也影响定振波的周期, 在动力方程中不考急铅直涡动雷诺力项后, 金诚成 一ㄹ]等于 1979 年得到:

$$
T=T_{\mathrm{d}} / \sqrt{1-\left(\nu, \times T_{\mathrm{a}} / 2 \pi\right)^{2}}
$$

式中 $T$. 为不考虑湖底摩揎力的周期. 相对于太湖的条件, 得到 $\left(\nu_{2} \cdot T_{\mathrm{a}} / 2 \pi\right)^{2} \approx 1.56 \times$ $10^{-2}$ 、因而在考虑湖底摩擦力作用时比不考结时大 $6 \mathrm{~min}$ 。 


\section{三、影响定振波因素的初步分析}

资料表明 -由相应频率的我面风速剪应力脉动所引起的太湖短周期谐被与风浪形成有 类似之处，但定振波的波长和周期具有比风浪更长而稳定的性质。由于剪应力脉动经常存 在, 所以，尽管在单位时间内短周期波动的振幅的衰碱速度比长周期振动为大, 但它却以振 幅变化不大的形式经常出现。而主振波则不同, 除了绞慢渐变外, 有时表现为振幅的突然增 大或衰减。对照自计水位资料及同步气象资料发现、这种突变与气压场、风场、降水的分布不 均匀并在几十分钟内发生突变有关。当二者位相一致时, 可引起振幅的突然增大。位相相反 时则引起振幅的突然减小。例如, 1984年5月12日18:20-18:40油车港观测点气压升高 2. $5 \mathrm{hPa} .50 \mathrm{~min}$ 内定振波振幅由 $10 \mathrm{~mm}$ 增加到 $90 \mathrm{~mm} ; 1986$ 年6月 24 日大浦观测点 14 时前 3 小 时, 风向W, 平均风速 $1.5 \mathrm{~m} / \mathrm{s} .14$ 时后, 转为 $\mathrm{SE}$, 平均风速 $5.3 \mathrm{~m} / \mathrm{s}$. 半小时内振幅由 $20 \mathrm{~mm}$ 上 升到80mm：1986年8月2日 14:45一-15:05.大浦观测点降办 $20 \mathrm{~mm}$ 。此时其他点无雨，该点定 振波振幅由 $25 \mathrm{~mm}$ 增加到 $90 \mathrm{~mm}$ 、使湖水舄部增加并澈发了定振波。

\section{四、几点认识}

（1）太湖系一浅水湖泊, 定振波作用明显, 若与风涌水作用迭加在一起, 所引起的水位增 减值相当大,可使工农业生产造成损失。如1949年1月25日夜，一次西南大风仅历时数小时， 湖水陡张1.5m 左右,使湖东的洞庭乡新塘圩全部被淹。1991年7月.太湖发生特大洪水,在 防洪排港时，由于未考虑定振波风涌水作用，白天筑堤排水，晚上一场南风、水漫堤埼,劳而 无功的现象在无锡湾、安亭湾频频发生.这一点应引起防汛部门的重视。

（2）定振波作用所引起的水平流速是相当可观的, 当振幅为 $10 \mathrm{~cm}$ 时, 最大流速可达 $21 \mathrm{~cm} / \mathrm{s}$ 。它为日益发展的拦围养殖提供了不可多得的水体交换条件。

(3)东太湖仅以一束水口与西太湖相连, 通常情况下, 东太湖的定振波有其自身的变化 规律、而长时间偏西大风时因受西太湖定振波作用的影响, 其振幅加大,周期延长。

(4)太湖定振波的变化规律呈浅水湖泊的显著特征,表现为周期变化大、衰减强烈。水深 变化 $0.2 \mathrm{~m}$, 周期变化 $22 \mathrm{~min}$, 而深水湖泊则不同, 如云南抚仙湖, 水深变化 $1 \mathrm{~m}$, 周期变化仅 $0.2 \mathrm{~min}$.太湖定振波的衰减以周期计算其速度是抏仙湖的 23 倍。

(5)同步穹料表明,定振波对湖流的流速、流向有影响、尤其在各进出湖河口更明显,能 使进出湖河流作反向流动。笔者在长广溪河口 (吴塘门桥上)曾测到表层流速 $24 \mathrm{~cm} / \mathrm{s}$ 的反向 流速。环保部门在计算污染物排放量时应注意到这一点,否则有些现象则无法解释。 
考文献

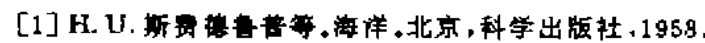

[2]官水政英(日)。海洋波动。北京,科学出版社.1984.

[3]中国科学完京京地理与湖泊研究所湖泊室著。江苏湖泊诘。席京。江苏科学技术出版社.19d2.

[4]中国科学院京京地理与湖泊研究所蓄.云南断陷湖泊环境与沉积。北京、科学出版社.1989.

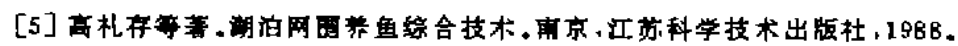

\title{
A PRELIMINARY STUDY ON SEICHES IN TAIHU LAKE
}

\author{
Zhang Wenhua
}

(Nanying Instituse of Gography and Limnology, Academia Sinica. Nanjing 210008)

\begin{abstract}
Characteristics of seiches in Taihu Lake are analysed preliminarily. The results show that: (1) The oscilation periads of seiches in East Taihu Lake vary from 180 to 291 minutes, writh an average value of 243 minutes and those in West Taihu Lake vary from 120 to 540 minutes with an average value of 400 minutes. (2) The observed maximum amplitude of seiches in Taihu Lake is about 120-130mm. (3) The characteristics of the seiches are estimated by the difference equection, and the estimating error in the periods is about 20 minutes. (4) The water current in the lake by the seiches is quite large. The maximum current speed is about $20 \mathrm{~cm} / \mathrm{s}$ when the seiche amplitude is $100 \mathrm{~mm}$. (5) The amplitude variation of seiches is related to the air pressure, wind field and rainfall above the lake.
\end{abstract}

Key words Seiche. Taihu Lake 